\title{
Epigenetic modification and uniparental inheritance of H19 in Beckwith-Wiedemann syndrome
}

\begin{abstract}
Daniel Catchpoole, Wayne W K Lam, Debbie Valler, I Karen Temple, Johanna A Joyce, Wolf Reik, Paul N Schofield, Eamonn R Maher
\end{abstract}

\author{
Cambridge University \\ Department of \\ Pathology, Tennis \\ Court Road, \\ Cambridge, UK \\ D Catchpoole \\ W W K Lam \\ E R Maher
}

Division of Medical

Genetics, Department

of Paediatrics and

Child Health,

University of

Birmingham,

Birmingham Women's

Hospital, Birmingham

B15 2TF, UK

W W K Lam

E R Maher

Molecular Genetics

Laboratory,

Addenbrooke's NHS

Trust, Cambridge, UK

$\mathrm{D}$ Valler

Wessex Regional

Genetics Service,

Southampton

University Hospitals

Trust, Southampton,

UK

I K Temple

Laboratory of Stem

Cell Biology,

Department of

Anatomy, Downing

Street, Cambridge

University,

Cambridge, UK

J A Joyce

P N Schofield

Laboratory of

Developmental

Genetics and

Imprinting, The

Babraham Institute,

Cambridge, UK

W Reik

Correspondence to: Professor Maher,

Birmingham.

Received 30 August 1996 Revised version accepted for publication 8 January 1997

\begin{abstract}
Beckwith-Wiedemann syndrome (BWS) is a congenital overgrowth syndrome associated with a characteristic pattern of visceromegaly and predisposition to childhood tumours. BWS is a genetically heterogeneous disorder; most cases are sporadic but approximately $15 \%$ are familial and a small number of BWS patients have cytogenetic abnormalities involving chromosome 11p15. Genomic imprinting effects have been implicated in familial and non-familial BWS. We have investigated the molecular pathology of 106 sporadic BWS cases; 17\% (14/83) of informative cases had uniparental disomy (UPD) for chromosome $11 \mathrm{p} 15.5$. In each case UPD appeared to result from a postzygotic event resulting in mosaicism for segmental paternal isodisomy. The critical region for isodisomy was refined to a $25 \mathrm{cM}$ interval between D11S861 and D11S2071 which contained the IGF2, H19, and $\mathrm{p} 57^{\mathrm{KIP} 2}$ genes. In three cases isodisomy for 11q markers was detected but this did not extend further than 11q13-q21 suggesting that complete chromosome 11 disomy may not produce a BWS phenotype. The allele specific methylation status of the $\mathrm{H} 19$ gene was investigated in 80 sporadic BWS cases. All 13 cases with UPD tested displayed hypermethylation consistent with an excess of paternal H19 alleles. In addition, five of $63(8 \%)$ cases with normal biparental inheritance had H19 hypermethylation consistent with an "imprinting centre" mutation (ICM) or "imprinting error" (IE) lesion. The phenotype of patients with putative ICM/IE mutations was variable and overlapped with that of non-UPD sporadic BWS cases with normal $\mathrm{H} 19$ methylation. However, exomphalos was significantly $(p<0.05)$ more common in the latter group. These findings may indicate differential effects on the expression of imprinted genes in chromosome $11 \mathrm{p} 15$ according to the precise molecular pathology. Analysis of H19
\end{abstract}

methylation is useful for the diagnosis of both UPD or altered imprinting in BWS and shows that a variety of molecular mechanisms may cause relaxation of IGF2 imprinting in BWS.

(F Med Genet 1997;34:353-359)

Keywords: Beckwith-Wiedemann syndrome; H19; uniparental inheritance

Genomic imprinting is a recently discovered mechanism by which the activity of genes may be altered epigenetically in a manner dependent on the parent of origin of each of the two alleles. Further work has implicated genes subject to imprinting in the control of embryonic growth and, of the genes now shown to be imprinted, eight have been shown to affect some aspect of cellular or organismal growth. ${ }^{1}$ Imprinted genes tend to be clustered in specific chromosomal locations, and currently there is evidence that such imprinted loci may be controlled by cis acting "imprinting centres" which are involved either in the maintenance or initiation of the imprint. ${ }^{2}$

The observation that the penetrance of some human genetic diseases was subject to a non-X linked parent of origin effect led to the realisation that dysregulation of the normal pattern of imprinting in certain key genes may lead to hyperplastic/trophic or frank neoplastic disease. ${ }^{3}$ Three human diseases, Angelman, Prader-Willi, and Beckwith-Wiedemann (BWS) syndromes have been extensively studied as paradigms of disordered genomic imprinting. ${ }^{4}$

BWS is a congenital overgrowth syndrome characterised by the association of gigantism, macroglossia, and visceromegaly with a variety of developmental anomalies such as exomphalos, umbilical hernias, hemihypertrophy, genitourinary abnormalities, and a predisposition to embryonal tumours. ${ }^{5}$ The genetics of BWS are complex. Most cases are sporadic, but approximately $15 \%$ are familial and a small number have chromosomal aberrations of chromosome $11 \mathrm{p}$. Clinical and molecular genetic studies suggest that the BWS gene, or 
genes, are imprinted as, in affected families, penetrance is usually more complete with maternal inheritance. ${ }^{6} 7$ Genomic imprinting effects have also been implicated in sporadic forms of the disease with a variety of mechanisms being implicated, ${ }^{8-16}$ including (1) uniparental disomy for $11 \mathrm{p}$, (2) paternally inherited duplications of $11 \mathrm{p} 15$, (3) maternally inherited balanced rearrangements of chromosome 11, and (4) putative "imprinting centre mutations" (ICM) or imprinting errors (IE), in which biallelic IGF2 expression is associated with hypermethylation of the IGF2 and H19 loci. IGF2 is paternally expressed in humans and mice, and while there is no evidence that circulating IGF-II is normally rate limiting on fetal growth, ${ }^{17}$ situations in which it is deleted from the genome result in marked fetal growth reduction. ${ }^{18}$ Analysis of tissue targeted expression of IGF-II suggests that local expression is a key factor in its biological effects. ${ }^{19} \mathrm{~A}$ reciprocal phenotype is seen with the equivalent manipulations of the maternally expressed $\mathrm{H} 19$ gene which maps $\sim 100 \mathrm{~kb}$ telomeric of IGF2. Regulation of IGF 2 and $\mathrm{H} 19$ expression may be closely and reciprocally linked. Maternal inheritance of a deletion of the $\mathrm{H} 19$ gene and flanking sequences causes expression from the maternal IGF2 allele (which is normally silenced).$^{20}$

In humans and mice, H19 and IGF2 show allele specific differences in DNA methylation, ${ }^{11}{ }^{21-25}$ and in previous studies we have shown an increase in DNA methylation at the IGF2/H19 loci in some sporadic BWS patients. ${ }^{26}$ Initially hypermethylation was only detected in disomic cases, but recently a small subgroup of non-disomic BWS patients with IGF2/H19 methylation changes were identified. ${ }^{16}$ These patients had the combination of a paternal methylation pattern on the maternal chromosome and biallelic IGF2 expression. It was proposed that these patients had mutations in a putative "imprinting centre" or errors in imprinting mechanisms. In addition, Morison et $a l^{7}$ have reported three patients with somatic overgrowth and nephromegaly or Wilms' tumour who had biallelic IGF2 expression but did not satisfy the diagnostic criteria for BWS. All three cases had partial hypermethylation at $\mathrm{H} 19$.

In the light of increasing evidence for the heterogeneity of BWS, we have further investigated the origin, frequency, significance, and associated phenotype of $\mathrm{H} 19$ methylation abnormalities in 106 sporadic BWS patients, the largest sample reported to date. These studies confirmed the usefulness of $\mathrm{H} 19$ methylation analysis for the molecular diagnosis of BWS, identified a further two cases with an ICM/IE, and refined the critical region for disomy to a $25 \mathrm{cM}$ interval between D11S861 and D11S2071.

\section{Methods}

PATIENTS

A total of 106 subjects ( 51 male, 55 female) with sporadic BWS were investigated. BWS was diagnosed according to previously defined criteria: (1) three major features (anterior abdominal wall defects, macroglossia and pre/postnatal growth $>90$ th centile), or (2) two major features plus three or more of: characteristic ear signs (ear lobe creases or posterior helical ear pits), facial naevus flammeus, hypoglycaemia, nephromegaly, and hemihypertrophy. ${ }^{4}$ All cases were sporadic with no family history of BWS, and only one patient had a cytogenetic abnormality, a male with a paternally derived duplication of $11 \mathrm{p} 15.5$. Peripheral blood for DNA analysis was obtained from each affected child and their parents. Of these patients, 49 were included in a previous study of uniparental disomy (UPD) in $\mathrm{BWS}^{12}$ with 34 of these being part of an investigation into H19/IGF2 methylation. ${ }^{26}$

H19 METHYLATION ANALYSIS

High molecular weight DNA was isolated from peripheral blood by standard methods. ${ }^{28}$ For analysis of H19 methylation, DNA samples $(8-10 \mu \mathrm{g})$ were digested with a large excess of PstI and SmaI as described previously. ${ }^{26}$ After Southern analysis and hybridisation with a $\mathrm{H} 19$ cDNA probe, the $\mathrm{H} 19$ methylation status, as designated by methylation indices (MI), was assessed by densitometry of autoradiographs and comparing the ratio of the $1.8 \mathrm{~kb}$ (uncut methylated) and $1.0 \mathrm{~kb}$ (cut unmethylated) fragments for deviation from a 1:1 ratio. MI values of less than 0.6 had previously been considered to be the upper limit for a normal population. $^{26}$

\section{MOLECULAR GENETIC INVESTIGATION}

All patients were screened for evidence of disomy at the tetranucleotide microsatellite polymorphism in tyrosine hydroxylase $(\mathrm{TH})$ and ApaI RFLP within exon 9 of IGF2 $2^{28}$ in chromosome $11 \mathrm{p} 15.5$. TH was amplified in PCR reactions as reported previously. ${ }^{11}$ To test for the ApaI RFLP site in the IGF2 gene DNA (100 ng) was amplified using 50 pmol primers (IGF2-F 5'-CTTGGACTTTGAGTCAAATTGG-3'; IGF2-R 5'-CCTCCTTTGGTCTTACTGGG-3') in $25 \mu$ mixtures containing $10 \mathrm{mmol} / 1 \mathrm{Tris} / \mathrm{HCl}, \mathrm{pH} 9.0,50 \mathrm{mmol} / 1$ $\mathrm{KCl}, 1.5 \mathrm{mmol} / 1 \mathrm{MgCl}_{2}, 0.01 \mathrm{w} / \mathrm{v} \%$ gelatin, 0.1 $\mathrm{v} / \mathrm{v} \%$ triton X-100, $250 \mu \mathrm{mol} / 1$ each $\mathrm{dNTP}$, and $0.5 \mathrm{U} \mathrm{Taq}$ polymerase. Thermocycling conditions involved 30 cycles of 60 seconds denaturation at $92^{\circ} \mathrm{C}, 60$ seconds annealing at $55^{\circ} \mathrm{C}$, and two minutes for elongation at $72^{\circ} \mathrm{C}$, concluding with a final extension period of five minutes.

To increase the informativeness for UPD detection, the extent of disomy was investigated using a series of microsatellite and RFLP markers from chromosome $11 \mathrm{p}$ and $11 \mathrm{q}$. The RsaI polymorphic fragment in exon 5 of $\mathrm{H} 19$ was amplified using 50 pmol of each primer (p3104F 5'-AGATTCAAAGCCTCCACGA3'; p3461R 5'-AGTGTTTATTGATGATGAGTCCAG-3') in the same reaction mixture as detailed above with the addition of: $10 \% \mathrm{v} / \mathrm{v}$ DMSO, $10 \% \mathrm{v} / \mathrm{v}$ glycerol, and $0.05 \% \mathrm{w} / \mathrm{v}$ polyoxyethylene ether (W-1) (Sigma; Poole, Dorset). In this case, thermocycling involved an initial denaturation period of three minutes at $94^{\circ} \mathrm{C}$ followed by 30 cycles of $96^{\circ} \mathrm{C}$ for $30 \mathrm{sec}-$ 


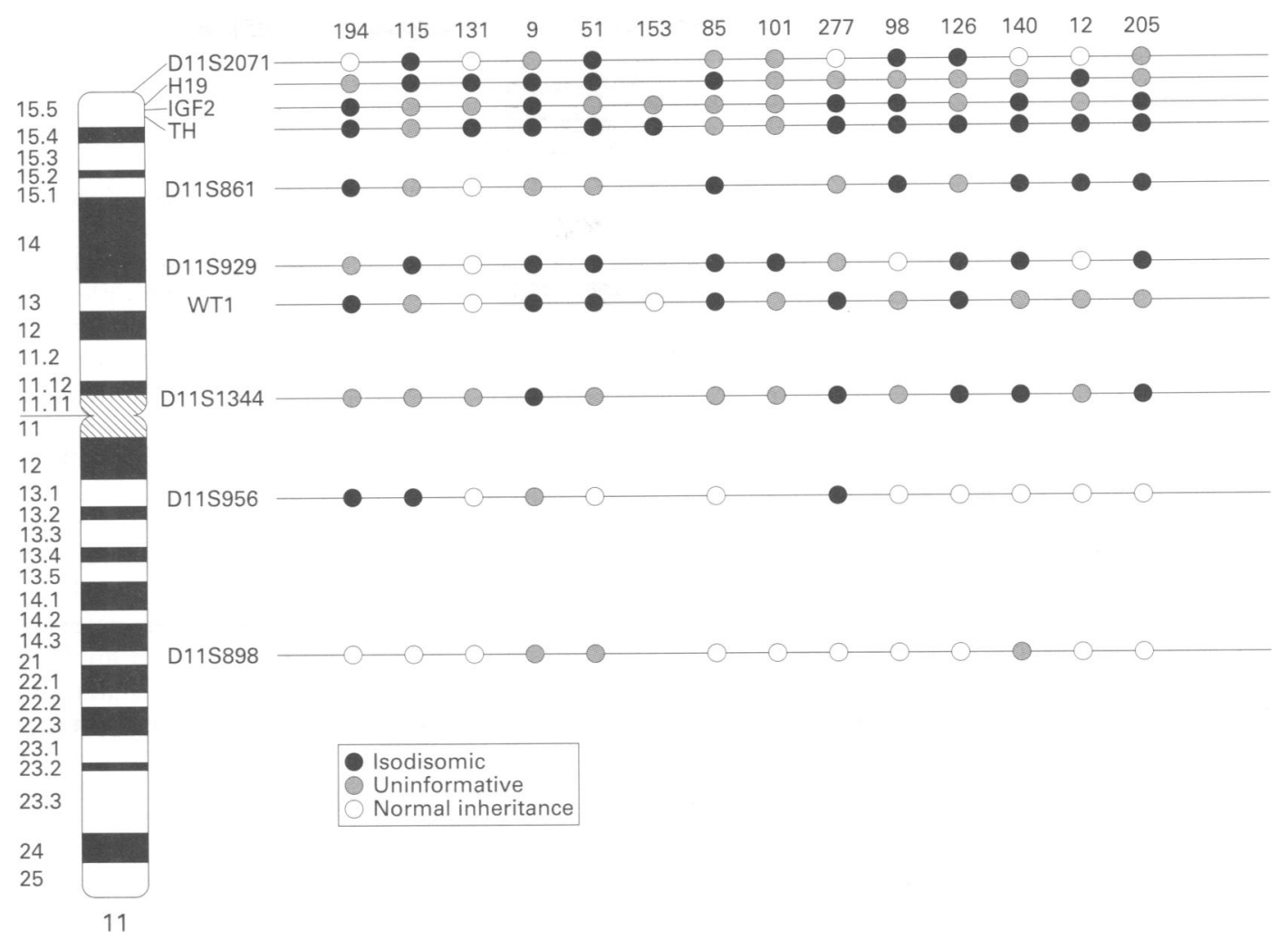

Figure 1 Map showing UPD in BWS patients as indicated by analysis of various chromosome 11 microsatellite (D11Snumbers) and RFLP polymorphic markers. Patient identification numbers are indicated at the top of each column. The H19, IGF2, and TH loci were within the disomic region in all cases and disomy extended onto 11q in three patients (194, 115 , and 277).

onds, $52^{\circ} \mathrm{C}$ for 60 seconds, and $72^{\circ} \mathrm{C}$ for two mintes, concluding with a 10 minute extension at $72^{\circ} \mathrm{C}$. Following the PCR of either IGF2 or $\mathrm{H} 19$ fragments, $10.5 \mathrm{ml}$ product was digested with $30 \mathrm{U} A p a \mathrm{I}(10 \mathrm{U} / \mu \mathrm{l})$ or $R s a \mathrm{I}(10 \mathrm{U} / \mu \mathrm{l})$ respectively in the appropriate reaction buffers according the supplier's conditions. Both digested and non-digested samples were electrophoresed through $2 \%$ agarose in TAE with DNA bands being visualised by ethidium bromide staining.

Amplification of the CA repeat within the WT1 gene (11p13) was performed essentially as previously outlined. ${ }^{30}$ The dinucleotide repeat polymorphisms D11S861, D11S956, and D11S2017 were amplified under conditions described by Hudson et al, ${ }^{31}$ Smith et al, ${ }^{32}$ and Browne et al, ${ }^{33}$ respectively. For analysis of the microsatellite polymorphisms at D11S929, D11S1344, and D11S898 the following primer sets were used: S929F 5'-AGG CCCTTCCAAGATCAG-3', S929R 5'-CCC AGTTGCCGAACTACC-3'; S1344F 5'-CCC TGAACTTCTGCATTCAC-3', S1344R 5'GCGCCTGGCTTGTACATATA-3'; S898F 5'- AGCACCATTTGCTGAGACTG-3', S89 8R 5'-TGTATTTGTA- TCGATTAACCAA CTT-3. ${ }^{33}$ DNA (50 ng) was amplified in $13 \mu \mathrm{l}$ reactions containing PCR buffer $(10 \mathrm{mmol} / \mathrm{l}$ Tris/ $\mathrm{HCl}, \mathrm{pH} 9.0,50 \mathrm{mmol} / \mathrm{KCl}, 1.5 \mathrm{mmol} / \mathrm{l}$ $\mathrm{MgCl}_{2}, 0.01 \% \mathrm{w} / \mathrm{v}$ gelatin, $0.1 \% \mathrm{v} / \mathrm{v}$ triton $\mathrm{X}-100), 10 \mathrm{pmol}$ of each primer, $125 \mu \mathrm{mol} / \mathrm{l}$ of each dNTP, and $0.25 \mathrm{U} \mathrm{Taq}$ polymerase. The samples were subjected to 30 PCR cycles of denaturation at $94^{\circ} \mathrm{C}$ for 45 seconds, annealing at $60^{\circ} \mathrm{C}$ for 30 seconds, and extension at $72^{\circ} \mathrm{C}$ for 30 seconds. Upon completion, a further five minutes $72^{\circ} \mathrm{C}$ extension was performed.

PCR products for each microsatellite marker were electrophoresed through 7.5 or $10 \%$ polyacrylamide (acrylamide:bis ratio 40:1, $1 \times$ TBE) depending on the size of separation required. Gels were cast in a $20 \mathrm{~cm} \times 20 \mathrm{~cm} \times$ $1 \mathrm{~mm}$ vertical gel system and run in $1 \times$ TBE. Samples $(10 \mu \mathrm{l})$ were mixed with $3 \mu \mathrm{l}(6 \times)$ gel loading dye $(15 \% \mathrm{w} / \mathrm{v}$ ficoll, $5 \mathrm{mmol} / \mathrm{l}$ EDTA, $0.1 \% \mathrm{w} / \mathrm{v}$ SDS, $0.25 \% \mathrm{w} / \mathrm{v}$ bromophenol blue, $0.25 \% \mathrm{w} / \mathrm{v}$ xylene cyanol) and electrophoresed at 100-120 volts for approximately 16 hours. Microsatellite bands were visualised by silver staining.

STATISTICAL ANALYSIS

Intergroup differences were compared using the chi-squared test with Yates' correction. Statistical significance was taken at the $5 \%$ level.

\section{Results}

UNIPARENTAL DISOMY IN BECKWITH-WIEDEMANN SYNDROME

A total of 69 of $83(83 \%)$ cases informative at TH or IGF2 had normal biparental inheritance with no evidence of paternal UPD. No cases of heterodisomy were identified but 14 (17\%) cases showed paternal isodisomy (figs 1 and 2). To investigate the origin and extent of paternal disomy a series of chromosome 11 polymorphic markers were analysed in these 14 cases. All showed mosaicism for partial paternal isodisomy suggesting that all UPD cases had arisen as a postzygotic event. The TH and 

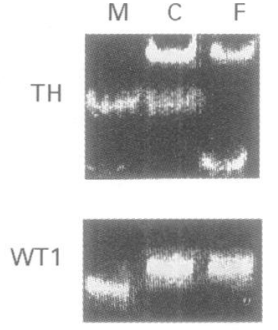

D11S1344

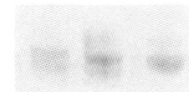

D1S956

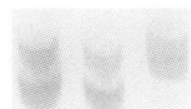

Figure 2 Molecular genetic analysis using chromosome 11 microsatellite markers and RFLPs. Inheritance of parental alleles in BWS patient 51, showing mosaicism. Tyrosine hydroxylase (TH) (11p15.5) and Wilms'tumour 1 (WT1) (11p13) are from ethidium bromide stained agarose gels, while D11S1344 (11p11) and D11S956 (11q13) are from $P A G E$ gels stained with silver. $M$, mother; $C$, affected child; $F$, father.

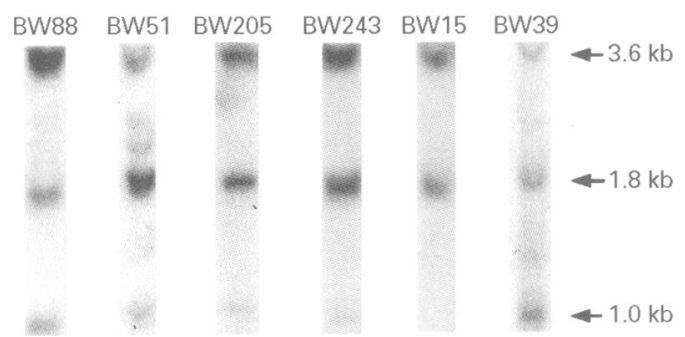

Figure 3 Increased H19 methylation in BWS patients. $B W 88$ and $B W 39$ are non-UPD patients with normal methylation patterns ( $M I=0.60$ and 0.49 respectively). $B W 51$ and $B W 205$ were identified as UPD (fig 1) and show hypermethylation at the $H 19$ locus. BW243 and $B W 15$ represent $B W S$ patients with normal inheritance of chromosome 11 p15 alleles but have increased H19 methylation (MI=0.87 and 0.93 respectively) indicative of an ICM or IE lesion.

IGF2 loci were included in the minimally disomic region in all cases and the smallest region for disomy was a $25 \mathrm{cM}$ region between D11S861 and D11S2071 (BW131) (fig 1). Disomy extended onto the long arm of chromosome 11 in three instances (BW 194,

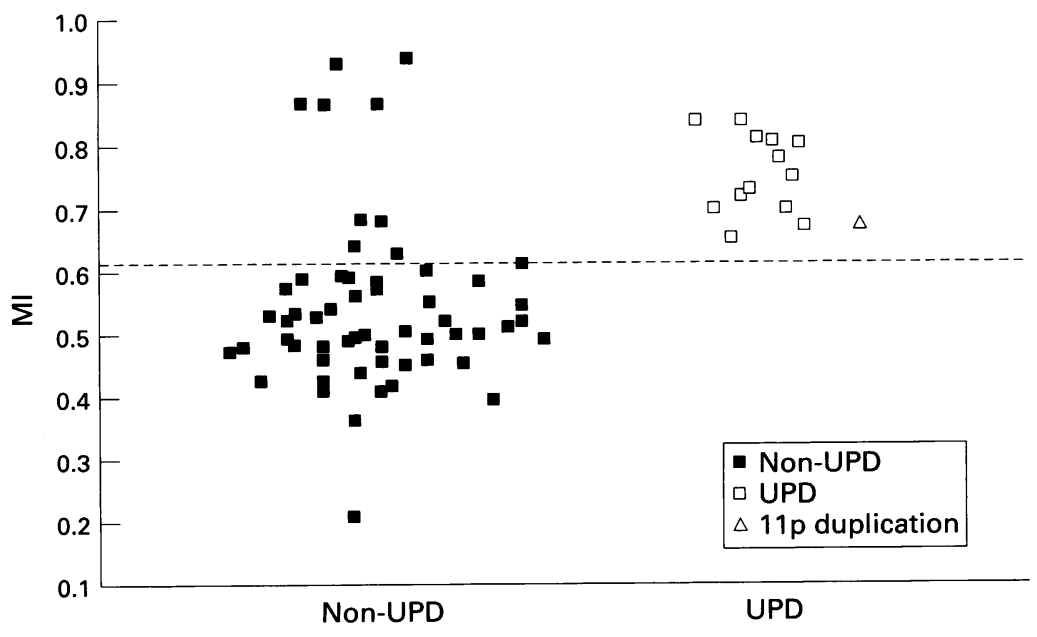

Figure $4 H 19$ methylation indices of BWS patients. $M I$ were derived as described in Materials and methods. The patient represented by the triangle was shown to have a paternally derived duplication of 11 p15.5 (MI=0.67).
BW115, BW277), but did not extend as far as $11 \mathrm{q} 21$ (D11S898) (fig 1).

H19 METHYLATION ANALYSIS

Allele specific methylation of the H19 promoter region was examined in the 80 BWS patient samples in which sufficient DNA was available for Southern analysis. Fig 3 illustrates typical examples; hypermethylation of the maternal allele of $\mathrm{H} 19$ is indicated by a reduction in intensity of the $1.0 \mathrm{~kb}$ digestion product. Methylation indices (MI) were derived from 63 patients informative for UPD analysis. In the 13 patients with paternal UPD analysed, the MI ranged between 0.65 and 0.84 and 40 patients, while most patients in whom paternal UPD had been excluded had a MI <0.64 (fig 4). A previously undescribed patient with paternally derived duplication of 11 p 15.5 had an MI of 0.67 , consistent with a 2:1 ratio of paternal (methylated) to maternal H19 (unmethylated) alleles. Five patients with normal biparental inheritance, including three reported previously, ${ }^{16}$ had a MI greater than those found in the UPD cases $(>0.84)$.

CLINICAL PHENOTYPE OF BWS SUBGROUPS

In a previous study we had found that hemihypertrophy was significantly more common and exomphalos less frequent in UPD cases than in non-UPD patients. ${ }^{11}$ The clinical phenotype of non-UPD patients with $(M I>0.84, n=5)$ and without $(M I<0.6, n=19)$ putative ICM/IE were compared. Postnatal growth $>90$ th centile was similar in both groups (4/5 and 16/19 respectively); birth weight tended to be higher in cases with $\mathrm{H} 19$ hypermethylation (4/5 and $5 / 19$ respectively had a birth weight $>90$ th centile; $\chi^{2}=2.85$, $0.05<\mathrm{p}<0.1)$. In addition, exomphalos was less common in patients with ICM/IE $(0 / 5$ versus $\left.13 / 19 ; \chi^{2}=4.96, \mathrm{p}<0.05\right)$. Wilms' tumour occurred in $1 / 5$ non-UPD patients with a $\mathrm{MI}>0.84,0 / 19$ non-UPD patients with $M I<0.6$, and $1 / 12$ UPD patients.

\section{Discussion}

UNIPARENTAL DISOMY IN BECKWITH-WIEDEMANN SYNDROME

Uniparental disomy (UPD) in humans has been thought to be caused primarily by meiotic non-disjunction events followed by trisomy or monosomy "rescue". UPD has been reported for 16 human chromosomes and has indicated the likelihood of imprinting effects in certain genome regions. ${ }^{34}{ }^{35}$ The proportion of UPD identified $(17 \%)$ in our informative BWS cases is comparable with that derived from smaller studies. ${ }^{912}$ To date all BWS patients with UPD have had partial (segmental) and somatically mosaic paternal isodisomy. This is in contrast to paternally derived UPD in Angelman syndrome, which is usually complete and results from errors during meiosis. The absence of complete chromosome 11 isodisomy or heterodisomy could reflect the infrequency of trisomy 11 compared to trisomy 15 , or more likely, that the presence of imprinted genes on chromosome $11 \mathrm{q}$ results in a non-BWS phenotype in patients with complete isodis- 
omy. Hence, Webb et $a l^{\beta 6}$ have reported a case of complete paternal chromosome 11 disomy as a result of trisomy 11 rescue which presented with prenatal growth retardation. Two loci for familial non-chromaffin paraganglioma (PGL1 and PGL2) have been mapped to chromosome $11 \mathrm{q} \cdot{ }^{37}{ }^{38}$ Familial paraganglioma only manifests when it is inherited from the father, suggesting that it is caused by mutations in an imprinted paternally expressed tumour suppressor gene. PGL2 maps to a $5 \mathrm{cM}$ region of $11 \mathrm{q} 13$ between D11S956 and PYGM but three of our patients were disomic at D11S956 (fig 1). PGL1, however, maps to chromosome $11 \mathrm{q} 21$ which was beyond the limits of disomy in our BWS patients. No other imprinted genes have been mapped to $11 \mathrm{q}$, but imprinted genes are frequently clustered and other genes may lie within this interval. The presence of imprinted genes distal to $11 \mathrm{q} 13$ may preclude the finding of complete paternal chromosome 11 disomy in people with a BWS phenotype.

Molecular genetic analysis of a BWS associated paternally derived duplication by Weksberg $e t a l^{14}$ showed that the duplicated region included genes distal to the calcitonin-A (CALCA) locus in $11 \mathrm{p} 15.4$. Analysis of the breakpoint regions of balanced translocations and pericentric inversions associated with BWS have indicated two breakpoint cluster regions, the most distal of which (BWSCR2) maps centromeric to a cluster of genes already known to be imprinted in the mouse, IGF2, $\mathrm{H} 19$, $\mathrm{p} 57^{\mathrm{KIP} 2}$, Ins, all of which are associated with embryonic growth. While IGF2 has been suggested as a candidate for the BWS locus, one familial study has reported exclusion of linkage to IGF $2^{39}$ and both biallelic and normal monoallelic IGF2 expression has been reported. ${ }^{40}$ Bischoff et $a l^{41}$ mapped the minimal disomic region in one BWS patient to an approximately $38 \mathrm{cM}$ region between D11S922 (11p15.5) and D11S904 (11p14p13). Our results refine the critical region for BWS still further to a $25 \mathrm{cM}$ interval between D11S861 (11p15.1) and the $11 \mathrm{p}$ telomeric microsatellite marker D11S2071. This region contains both IGF2 and $\mathrm{H} 19$ and the BWSCR2 region defined by Redeker et al. ${ }^{42}$

H19 METHYLATION AND IGF2 EXPRESSION.

Biallelic IGF 2 expression has been found in tissues from BWS patients, ${ }^{160}$ and is similarly dysregulated in Wilms' tumours. Inappropriate expression of IGF2 from the maternal allele has been shown to correlate with methylation of the promoter region of the neighbouring H19 gene in Wilms' tumour ${ }^{434}$ and in BWS. ${ }^{16}$ Hypermethylation of $\mathrm{H} 19$ is associated with transcriptional inactivity and hypermethylation of a region of exon 9 in the human IGF2 gene is associated with active transcription. ${ }^{24} \mathrm{Re}$ moval of methylation by germline deletion of the DNA methylase enzyme results in IGF2 inactivity and transcription of the normally silent paternal $\mathrm{H} 19$ gene, ${ }^{45}$ and deletion of the $\mathrm{H} 19$ gene results in IGF2 overexpression. ${ }^{20}$ In addition, a small number of BWS patients (5-10\%) have normal biallelic inheritance and H19 hypermethylation which exceeds that found in mosaic UPD patients. By analogy with similar findings in Angelman/Prader-Willi patients, ${ }^{46}$ it has been proposed that these changes may result from alteration of an imprinting control region or imprinting errors. ${ }^{16}$ In this context all five BWS patients identified so far have been sporadic cases, so there is, as yet, no definitive evidence as to whether possible ICM/IE lesions are genetic or epigenetic.

To date all three BWS patients with an ICM/IE who are informative for IGF2 polymorphic marker studies have shown biallelic IGF2 expression ${ }^{16}$ (unpublished observations). However, the clinical phenotype of these patients is not uniform and although four had classical BWS features, one patient displayed an incomplete phenotype with mild macroglossia and an umbilical hernia but normal prenatal growth. Recently Morison et $a l^{77}$ have described non-classical BWS overgrowth patients with biallelic IGF2 expression and $\mathrm{H} 19$ hypermethylation. However, the degree of hypermethylation was less than that seen in our ICM/IE patients. In addition to the five patients with markedly increased H19 hypermethylation ( $M I>0.84)$, several non-disomic patients had methylation indices slightly higher than the previously described upper limit of normal (0.6). Morison et $a l^{27}$ suggested that patients with partial hypermethylation, such as these, may be mosaic for imprinting mutations. In addition to putative ICM or IEs causing aberrent H19/IGF2 methylation patterns and IGF2 overexpression, we have also detected biallelic IGF2 expression in some non-UPD BWS patients with normal $\mathrm{H} 19$ methylation (Joyce et al, submitted) and Brown et $a l^{47}$ have described similar findings with normal H19 expression in a BWS family with a chromosome 11 inversion. These findings indicate that a variety of $\mathrm{H} 19$ dependent and independent mechanisms may lead to biallelic IGF2 expression in BWS.

Although biallelic IGF2 expression has been reported in complete and incomplete forms of sporadic BWS, normal imprinting of the IGF2 gene has also been reported, ${ }^{40}$ perhaps indicating that loss of IGF2 imprinting is not the only mechanism from which a BWS phenotype can result. In addition to IGF2 and $\mathrm{H} 19$, other imprinted genes such as $\mathrm{p} 57^{\mathrm{KIP} 2}$ map to the minimally duplicated/disomic region. ${ }^{48}$ The phenotype of BWS is variable and so the particular features may depend on the extent of disomy or the precise pathogenetic mechanism, if this resulted in differential changes in the expression of other imprinted genes.

\section{PHENOTYPE/GENOTYPE CORRELATION}

The identification of clear genotype/phenotype correlations would enhance clinical management and provide evidence to support the hypothesis that the precise BWS phenotype may be determined by the specific molecular pathology of BWS. Two studies have reported a high incidence of Wilms' tumour in BWS patients with UPD $(40 \%$ and $50 \%$ respectively) $)^{1011}$ and our results continue to suggest that although Wilms' tumour may be 
more common in children with BWS, the actual risk $(\sim 8 \%)$ is lower than previous estimates, which may have reflected an ascertainment bias. In addition, the occurrence of a Wilms' tumour in a non-UPD BWS patient shows that the tumour risk is not confined to BWS UPD patients. We have previously observed that hemihypertrophy was significantly more common and exomphalos was less common in the disomic group than the non-UPD group. These findings were attributed to the the mosaic nature of UPD, so it was surprising that there was evidence to suggest that exomphalos was less common in nonUPD cases with $\mathrm{H} 19$ hypermethylation than in those with normal methylation. This may indicate that exomphalos is not simply a consequence of increased intra-abdominal pressure owing to hypertrophy, but may involve the failure of specific processes such as cell adhesion or migration which could be affected by alterations in the activity of other imprinted genes at the locus. Further studies are needed to confirm these findings, to determine the risk of neoplasia in patients with ICM/IE, and to elucidate the mechanisms for these genotypephenotype correlations. Knowledge of the imprinting status of genes such as $\mathrm{H} 19$ and p5 $7^{\mathrm{KIP} 2}$ in patients with UPD and ICM/IE compared to non-UPD without H19 methylation might provide insight into the cause of these associations. It is interesting to note that H19 expression is low or absent in the class of patients with a low incidence of exomphalos (that is, UPD and ICM/IE patients).

In summary, we have shown that $\mathrm{H} 19$ methylation analysis is a reliable method for detecting UPD in BWS patients and also detects small numbers of patients with "imprinting centre mutations" (5-10\%). We studied methylation status in blood DNA and it is possible that H19 methylation may vary between tissues. However, to date, the results of $\mathrm{H} 19$ methylation analysis in cultured fibroblasts $(n=3)$ from non-UPD patients is consistent with those obtained from blood DNA. The postzygotic origin of paternal UPD in BWS may indicate that complete isodisomy or heterodisomy of chromosome 11 has a low viability or non-BWS phenotype. Careful correlation of the clinical phenotype with the molecular pathology may provide an insight into the aetiology of the variable expression of BWS and determine what screening should be offered to BWS children. Definition of the critical region of chromosome $11 p$ for UPD in BWS will provide a basis for understanding the aetiology of BWS, and the detailed comparison of the clinical features of BWS patients with variable lengths of segmental isodisomy may identify target regions for other imprinted genes on chromosome 11. Similarly, further studies of the phenotype and heterogeneity of molecular mechanisms in non-BWS UPD may provide critical insights into the role of IGF2, $\mathrm{H} 19, \mathrm{p} 57^{\mathrm{KIP} 2}$, and other imprinted genes in various facets of the BWS phenotype.

We thank the many colleagues who referred patients and the Wellcome Trust and East Anglian Regional Health Authority for financial support. WR acknowledges the support of Action Research.

1 Barlow DO. Gametic imprinting in mammals. Science 1995;270:1610-13.

2 Efstradiatis A. Parental imprinting of autosomal mammalian genes Curr Opin Genet Dev 1994;4:265-80.

3 Reik W. Genomic imprinting and genetic disorders in man. Trends Genet 1989;5:331-6.

4 Tycko B. Genomic imprinting; mechanism and role in human pathology. Am $\mathcal{F}$ Pathol 1994;144:431-43.

5 Elliott M, Maher ER. Beckwith-Wiedemann syndrome. $f$ Med Genet 1994;31:560-4.

6 Moutou C, Junien C, Henry I, Bonaiti-Pellie C. Beckwith Wiedemann syndrome: a demonstration of the mechanisms responsible for the excess of transmitting females. $f$ Med Genet 1992;29:217-20.

7 Viljoen D, Ramesar R. Evidence for paternal imprinting in familial Beckwith-Wiedemann syndrome. 7 Med Gene 1992;29:221-5.

8 Henry I, Bonaiti-Pellie C, Chehensse V, et al. Uniparental paternal disomy in a genetic cancer-predisposing syndrome. Nature 1991:351:665-7.

9 Nystrom A, Cheetham JE, Engstrôm W, Schofield PN. Molecular analysis of patients with Wiedemann-Beckwith syndrome II: paternally derived disomies of chromosome 11. Eur f Pediatr 1992;151:511-14

10 Henry I, Puesch A, Riesewijk A, et al. Somatic mosaicism fo partial paternal isodisomy in Wiedemann-Beckwith syndrome: a post fertilisation event. Eur $\mathcal{f}$ Hum Gene 1993;1:19-29.

11 Schneid H, Seurin D, Vazquez MP, Gourmelen M, Cabrol $\mathrm{S}$, Le Bouc Y. Parental allele specific methylation of the human insulin-like growth factor II gene and Beckwithhuman insulin-like growth factor II gene and Beckwitemann syndrome. $\mathcal{F}$ Med Genet 1993;30:353-62.

12 Slatter RE, Elliott M, Welham $\mathrm{K}$, et al. Mosaic uniparental disomy in Beckwith-Wiedemann syndrome. 7 Med Gene 1994;31:749-53

13 Brown KW, Gardner A, Williams JC, Mott MG, McDermott A, Maitland NJ. Paternal origin of $11 \mathrm{p} 15$ duplication in the Beckwith-Wiedemann syndrome. A new case and review of the literature. Cancer Genet Cytogenet 1992;58:6670.

14 Weksberg R, Teshima I, Williams B, et al. Molecular characterisation of cytogenetic alterations associated with the Beckwith-Wiedemann syndrome phenotype refines the Beckwith-Wiedemann syndrome phenotype refines the localisation and suggests the gen

15 Norman AM, Read AP, Clayton-Smith J, Andrews T, Donnai D. Recurrent Wiedemann-Beckwith syndrome with inversion of chromosome (11)(p11.2p15.5). Am f Med Genet 1992;42:638-41.

16 Reik W, Brown K, Schneid H, Le Bouc Y, Bickmore W, Maher ER. Imprinting mutations in the BeckwithWiedemann syndrome suggested by an altered imprinting pattern in the IGF2-H19 domain. Hum Mol Genet 1995;4: 2379-85.

17 Gluckman PD, Ambler GR What is the function of circulating IGF-II in postnatal life? Mol Cell Endocrinol 1993;92: C1-3.

18 de Chiara TM, Efstradiatis A, Robertson E. Parenta imprinting of the mouse insulin-like growth factor II gene. Cell 1991;64:849-59.

19 Ward A, Bates P, Fisher R, Richardson L, Graham C. Disproportionate growth in mice with igf-2 transgenes. Proc Natl Acad Sci USA 1994;91:10365-9.

20 Leighton PA, Ingram RS, Eggenschwiler J, Efstratiadis A, Tilghman SM. Disruption of imprinting caused by deletion of the H19 gene region in mice. Nature 1995;375:34-9.

21 Sasaki H, Jones PA, Chillet JR, et al. Paternal imprinting: potentially active chromatin of the repressed allele of the mouse igf2 gene. Genes Dev 1992;6:1843-56.

22 Bartolomei, MS, Webber AL, Brunkow ME, Tilghman SM. Epigenetic mechanisms underlying the imprinting of the mouse H19 gene Genes Dev 1993;7:1663-73.

23 Ferguson-Smith AC, Sasaki H, Cattanach BM, Surani A. A parental-origin-specific epigenetic modification of the mouse H19 gene. Nature 1993;362:751-5.

24 Feil R, Walter J, Allen ND, Reik W. Developmental contro of allelic methylation in the imprinted mouse IGF2 and $\mathrm{H} 19$ genes. Development 1994;120:21933-43.

25 Brandeis M, Kafri T, Ariel M, et al. The ontogeny of allele specific methylation associated with imprinted genes in the mouse. EMBO ₹ 1993;12:3669-77.

26 Reik W, Brown KW, Slatter RE, Sartori P, Elliott M, Maher ER. Allelic methylation of H19 and IGF2 in the Beckwith Wiedemann syndrome. Hum Mol Genet 1994;3:1297-301.

27 Morison IM, Becroft D, Taniguchi T, Woods CG, Reeve A Somatic overgrowth associated with overexpression of insulin-like growth factor II. Nat Med 1996;2:311-16.

28 Sambrook J, Fritsch EF, Maniatis T. Molecular cloning - a laboratory manual. New York: Cold Spring Harbor Laboratory Press, 1989:31-9.

29 Todokoro K, Fujii H, Inoue T, Yamada M. Polymerase chain reaction (PCR) for detection of ApaI polymorphism at the insulin like growth factor II gene (IGF2). Nucleic Acids Res 1991;19:6967.

30 Haber DA, Buckler AJ, Glaser T, et al. An internal deletion within an $11 \mathrm{p} 13$ zinc finger gene contributes to the dvelopwithin an 11p13 zinc finger gene contributes to 
31 Hudson TJ, Engelstein M, Lee MK, et al. Isolation and chromosomal assignment of 100 highly informative human chromosomal assignment of 100 highly informative human simple

32 Smith MW, Clark SP, Hutchinson JS, et al. A sequenceSmith $\mathrm{MW}$, Clark SP, Hutchinson JS, et al. A sequence-
tagged site map of human chromosome 11. Genomics 1995;

33 Browne DL, Smith EA, Dietz-Band J, Reithmann HC, Phromchotikul T, Litt M. Dinucleotide repeat polymorphism at the human chromosome $11 \mathrm{p}$ teleomere (D11S2071). Genomics 1995;25:600-1.

34 Coullin P, Guern EL, Vignal A, et al. Assignment of 112 microsatellite markers to 23 chromosome 11 subregions delineated by somatic hybrids: comparison with the genetic map. Genomics 1994;21:379-87.

35 Ledbetter DH, Engel E. Uniparental disomy in humans: development of an imprinting map and its implications for prenatal diagnosis. Hum Mol Genet 1995;4:1757-64

36 Webb A, Beard J, Wright C, Robson S, Wolstenholme J, Goodship J. A case of paternal uniparental disomy for Goodship J. A case of paternal uniparental
chromosome 11. Prenat Diagn 1995;15:773-7.

37 Heutink P, van der Mey AGL, Sandkuijl LA, et al. A gene subject to genomic imprinting and responsible for paragangliomas maps to chromosome 11q23-qter. Hum Mol Genet 1992;1:7-10

38 Mariman ECM, van Beersum SEC, Cremmers CWRJ, Struycken PM, Ropers HH. Fine mapping of a putatively imprinted gene for familial non-chromaffin paragangliomas to chromosome 11q13.1: evidence for genetic heterogeneity. Hum Genet 1995;95:56-62.

39 Nystrom A, Hedborg F, Ohlsson R. Insulin-like growth factor 2 cannot be linked to a familial form of BeckwithWiedemann syndrome. Eur f Pediatr 1994;153:574-80.
40 Weksberg R, Shen DR, Fei YL, Song QL, Squire J. Disruption of insulin-like growth factor 2 imprinting in Beckwith Wiedemann syndrome. Nat Genet 1993;5:143-50.

41 Bischoff FZ, Feldman GL, McCaskill C, Subramanian S, Hughes MR, Shaffer LG. Single cell analysis demonstrating somatic masaicism involving $11 \mathrm{p}$ in a patient with paternal isodisomy and Beckwith-Wiedemann syndrome. Hum Mol Genet 1995;4:395-9.

42 Redeker E, Alders M, Hoovers JMN, Richard CW III, Westerveld A, Mannens M. Physical mapping of 3 candidate tumour suppressor genes relative to BWS associcandidate tumour suppressor genes relative to BWS associ-
ated chromosomal breakpoints at $11 \mathrm{p} 15.3$. Cytogenet Cell Genet 1995;68:22-5.

43 Moulton T, Crenshaw T, Hao Y, et al. Epigenetic lesions at the H19 locus in Wilms' tumour patients. Nat Genet 1994; 7:440-7.

44 Steenman MJC, Rainier S, Dobry CJ, Grundy P, Horon I, Feinberg, AP. Loss of imprinting of IGF2 is linked to reduced expression and abnormal methylation of $\mathrm{H} 19$ in Wilms tumour. Nat Genet 1994;7:433-9.

$45 \mathrm{Li} \mathrm{E}$, Beard C, Jaenisch R. Role for DNA methylation in genomic imprinting. Nature 1993;366:362-5.

46 Buiting K, Saitoh S, Gross S, et al. Inherited microdeletions in the Angelman and Prader-Willi syndromes define an imprinting centre on human chromosome 15. Nat Genet imprinting centre

47 Brown KW, Villar AJ, Bickmore W, et al. Imprinting mutation in the Beckwith-Wiedemann syndrome leads to biallelic IGF2 expression through a H19-independent pathway. Hum Mol Genet 1996;5:2027-32.

48 Matsouka et al. Proc Natl Acad Sci USA 1996;93:3026-30. 